\title{
Design-Based Research in Designing the Model for Educating Simulation Facilitators
}

Jaana-Maija Koivisto', Leena Hannula ${ }^{1}$, Rikke Buus Bøje ${ }^{2}$, Stephen Prescott ${ }^{3}$, Andrew Bland ${ }^{3}$, Leena Rekola ${ }^{1}$, Päivi Haho ${ }^{1}$

Corresponding author

Jaana-Maija Koivisto, jaana-maija.koivisto@metropolia.fi

Jaana-Maija Koivistoํㅗㄱ Senior lecturer (email: jaana-maija.koivisto@metropolia.fi)

Leena Hannula1 Senior lecturer (email: leena.hannula@metropolia.fi)

Rikke Buus Bøje² Senior lecturer (email: ribs@via.dk)

Stephen Prescott ${ }^{3}$ Senior lecturer (email: s.f.prescott@hud.ac.uk)

Andrew Bland ${ }^{3}$ Senior lecturer (email: a.j.bland@hud.ac.uk)

Leena Rekola ${ }^{1}$ Principal lecturer (email: leena.rekola@metropolia.fi)

Päivi Haho ${ }^{1}$ Principal lecturer (email: paivi.haho@metropolia.fi)

1 Metropolia University of Applied Sciences PL 400000079 Metropolia Helsinki, Finland

${ }^{2}$ VIA University College, School of Nursing Randers, Jens Otto Krags Plads 3, 8900 Randers, Denmark

${ }^{3}$ School of Human and Health Sciences, University of Huddersfield, Queensgate, Huddersfield, HD1 3DH, United Kingdom

\section{Abstract}

The purpose of this article is to introduce the concept of design-based research, its appropriateness in creating education-based models, and to describe the process of developing such a model. The model was designed as part of the Nurse Educator Simulation based learning project, funded by the EU's Lifelong Learning program (2013-1-DK1-LEO05-07053). The project partners were VIA University College, Denmark, the University of Huddersfield, UK and Metropolia University of Applied Sciences, Finland. As an outcome of the development process, "the NESTLED model for educating simulation facilitators" (NESTLED model) was generated. This article also illustrates five design principles that could be applied to other pedagogies.

\section{Keywords}

Design-based research; educational model; simulation-based learning; simulation facilitator; simulation educator; competencies 


\section{Introduction}

The use of simulation-based learning (SBL) in the education of nurses and allied health professionals has increased rapidly over the last decade. Simulation pedagogy is considered a good solution to overcoming the many problems related to nursing education today (Adamson, 2009). Simulation improves nursing students' knowledge, confidence, competence and self-efficacy (Cant \& Cooper, 2017). The literature, however, reveals no consensus on what is needed to effectively deliver a simulation or how to train nursing educators to use (SBL). It has been recognized that there is a need to clarify the existing terminology that is associated with simulation-based learning (Bland et al., 2014) and to improve understanding of simulation pedagogy and the learning theories to which it is linked (Clapper, 2010; Roberts \& Greene, 2011; Walsh, 2011). Additional enquiry is necessary to illuminate further the conceptual framework of simulation (LaFond \& Van Hulle, 2012) and the attributes that underpin the foundations of SBL (Bland et al., 2011).

Simulation pedagogy is widely used in nursing education but each teacher's knowledge and skills relating to its use may vary substantially. Effective use of SBL is complex, and educator preparation is recognized as being vital (Anderson et al., 2012; Cant \& Cooper, 2009; Jeffries et al., 2008; Kaakinen \& Arwood, 2009). Crucially, educators need more preparation to deliver SBL than simply learning how to use a high-fidelity manikin. Importantly, it should be recognised that SBL does not necessarily involve the use of high-fidelity manikins.

There is a recognized need to improve simulation practice. As a consequence the International Nursing Association for Clinical Simulation and Learning (INACSL) has developed the INACSL Standards of Best Practice for simulation. These standards were designed for advancing the science of simulation, sharing best practices, and to providing guidelines for implementation and training INACSL (2016).

As a whole, there is limited research on how health professionals and teachers should be educated or trained to use simulation pedagogy. Some studies identify that simulation is best learned by practical training with feedback from simulation experts (Anderson et al., 2012; Bentley \& Seaback, 2011). Fisher (2007) describes an online simulation tool created to teach educators how to use simulation and to help them to create the content for their SBL event. However, this kind of training does not teach the theoretical background of simulation pedagogy. Moreover, it does not include debriefing and evaluation skills considered as important attributes of SBL (Topping et al., 2015).

Competence-based approaches and models of education, as well as human resource management (in a broader sense), have gained popularity in the last thirty years (Boyatzis, 1982; Mulder, 2012; 2014; Mulder et al., 2007; Spencer \& Spencer, 1993; Vathanophas \& Thai-ngam, 2007; Zemke, 1982). The notion of competency pertains to the integral capability of persons to perform adequately in a given context (Muller, 2012). According to Boyatzis (1982) a competency characterizes ability. Spencer and Spencer (1993) identified five characteristics of competency: motives, traits, selfconcept, knowledge and skills. Motives, traits and self-concept competencies are hidden, deeper and central to personality, whereas knowledge and skill competencies 
tend to be visible and relatively obvious characteristics. Thus, knowledge and skill competencies are rather easy to develop through training (Spencer \& Spencer, 1993).

The need to develop educator competency to facilitate simulation-based learning in nurse education was a starting point for the Nurse Educator Simulation based learning (NESTLED) project. The common goal of the project partners at VIA University College in Denmark, the University of Huddersfield in the UK and Metropolia University of Applied Sciences in Finland was to improve the education of nurse educators who use simulation-based learning. As a result, the NESTLED project team developed a model for preparing nurse educators to effectively use simulation-based learning. The development process began with a systemized rapid review and synthesis (Topping et al., 2015) which identified a list of competencies required of nurse educators. The competences were categorized under the headings knowledge, skills, behaviours, and comportment. Following the identification of these competencies, design-based research (DBR) was considered as an appropriate methodological framework (discussed within section 2) to guide the development and testing of the NESTLED model.

The definitions of the terminology used in this article are:

- NESTLED model: the overall outcome of the NESTLED project, i.e. the program and the results of the systematic review, including the identified competencies.

- NESTLED program: the eight sessions (including those elements considered compulsory and where there is some flexibility in delivery and content).

- NESTLED project team: researchers and simulation educators from VIA University College, Denmark; University of Huddersfield, UK; and Metropolia University of Applied Sciences, Finland.

- Simulation educator: person delivering the NESTLED program.

- Simulation facilitator: participant undertaking the NESTLED program.

- Student: those for whom the delivery of simulation-based learning is intended.

\section{Framework}

In the development of the NESTLED model, a design-based research methodology was adopted due to its systematic and flexible method of improving teaching practices (Amiel \& Reeves, 2008; Wang \& Hannafin, 2005). The design-based research methodology is well-suited to learning environments and educational research because it draws from multiple disciplines (Koivisto et al., 2018; Sandoval \& Bell, 2004) including health and learning sciences. Previously, in the field of nursing, designbased research has been used to generate principles for the design of educational simulation games (Koivisto et al., 2018). Our aim was to advance the theory about the competencies required of educators when delivering SBL and, based on this knowledge, design and develop an educational model for teaching SBL to nurse educators. The scientific community can use this knowledge as it directly influences learning practices in educational organizations.

Design-based research uses iterative cycles to analyse, design, implement and redesign (Amiel \& Reeves, 2008; Wang \& Hannafin, 2005). Cycles are grounded in development needs analysis, solution construction, solution testing, refining, reflection 
and reporting. In each cycle, data is collected and analysed for the following planning phase. Research is carried out in real-life settings and situations. In the real-life situations, the learning can be absorbed even better and detected by appropriate research and development topics. This kind of study relies on collaboration between practitioners and researchers (Barab \& Squire 2004; Wang \& Hannafin 2005).

The goal of design-based research is to generate reusable design principles (Reeves, 2006), and the outcomes of design-based research are the design principles that are generated based on the knowledge gained through long-term engagement in iterative cycles (Amiel \& Reeves, 2008; Reeves, 2006; Wang \& Hannafin, 2005). Designers can make changes to the initial design based on the limitations that appear during the iterative cycles, which in turn improves the final outcomes (Amiel \& Reeves, 2008; Reeves, 2006; Wang \& Hannafin, 2005). The principles can be used by others when applying the appropriate knowledge to a specific situation in the future (Plomp, 2013).

This project included the following five phases:

1. Systematic literature review

2. Analysis of current education programs

3. Development of a prototype

4. Testing of the prototype

5. Analysis of the test and refining of the prototype

The rapid review and synthesis (Topping et al. 2015) fulfilled the requirements of phase one. This was followed by analysis of education programs as required by the conditions for EU Transfer of Innovation funding (phase 2). Phase 3 involved the development of a program operationalizing the NESTLED model into a deliverable prototype-the NESTLED program. During phase 4 the NESTLED program was tested in three different countries (Denmark, Finland and Estonia). Following this 'pilot testing' and analysis of the data obtained, the program was refined further, and the design of the final NESTLED program confirmed (phase 5).

The iterative phases of this project allowed the international research team to make necessary changes to the design at any stage of the process. In each cycle, data was collected and analysed, and new design principles were applied to the next phase. The NESTLED project included a multi-method approach used by combining qualitative and quantitative data (see Barab \& Squire, 2004; Wang \& Hannafin, 2005). The data collection methods consisted of focus group interviews and questionnaires (pre- and post-program). Research was carried out in real-life settings in three different countries (Denmark, Estonia and Finland). Collaboration between experienced practitioners and researchers was emphasized (Barab \& Squire, 2004; Wang \& Hannafin, 2005). In this study, the project team consisted of simulation educators and researchers. The simulation educators in this study were senior lecturers. They were all experienced simulation facilitators who taught nurse educators to become simulation facilitators, and thus their opinions were important in the design process (Amiel \& Reeves, 2008). Researchers were responsible for data collection, analysis and reporting the results. The communication between project partners included twenty online meetings. Five face-to-face meetings were organized in Denmark, the UK and Finland between 2013 and 2015. Information was also shared through a NESTLED project website hosted by VIA University College. In addition to these 
interactions, numerous telephone calls and on-line meetings were arranged, and emails exchanged.

\section{Phases 1 and 2}

The design of the NESTLED model was based on the systemized rapid review and synthesis (Topping et al., 2015) and refinement of the existing training programs at the University of Huddersfield, Metropolia University of Applied Sciences and VIA University College. The rapid review and synthesis concluded that a simulation facilitator's knowledge base should consist of learning theories and strategies, an understanding of curriculum development and integration, group dynamics, and realworld examples for scenario development. The skills and behaviours needed to facilitate simulation based learning are the ability to deliver simulation, skills to support students, and ability to support reflection. According to our rapid review and synthesis (Topping et al., 2015), comportment describes the individual characteristics of a simulation facilitator. A facilitator should be able to create emotional safety, bring theory and practice together, and have a student-centred approach to teaching. The facilitator should have a passion for teaching and be a role model. Simulation sessions may not always run according to plan, so adaptability is also an important aptitude (Topping et al., 2015).

In addition, to design the NESTLED model, existing training for simulation facilitators at the University of Huddersfield, Metropolia University of Applied Sciences and VIA University College were reviewed. Content, modes of delivery, teaching and learning strategies, materials and equipment were compared and refined. Project partners worked together in a workshop, which improved consistency and fostered the development of a sustainable "community of practice".

\section{Phase 3}

The NESTLED model was operationalized into a deliverable prototype (from now on referred to as the NESTLED program). New pedagogical materials were developed . In addition, team-teaching was used as a strategy to deliver the NESTLED program in order to maximize the capabilities of simulation facilitators to deliver high-quality education. The prototype consisted of eight sessions (Table 1). The competencies identified by Topping et al. (2015) were integrated across the eight sessions. Different pedagogical solutions were used, such as pre-reading material, lectures, tutorials, and the use of an internet-based learning environment, individual written assignments and assessment of participants.

\section{[INSERT TABLE 1 HERE]}

At the beginning of the NESTLED project, members of the University of Huddersfield had over twenty years of experience combined in simulation-based learning and using it to teach clinical skills. Metropolia University of Applied Sciences had been using simulation-based learning for over a decade but only ten teachers were actively using it to teach decision-making and interaction skills, teamwork and theoretical subjects, in addition to clinical skills. At VIA University College, the teachers from all the schools of nursing had been using simulation-based learning since 2008, but only a few of them had undertaken any courses connected to the use of simulation pedagogy or the use of simulation equipment. Tallinn Health Care College, Estonia was one of the 
testing sites. It had only recently started to utilize simulation based learning; however, it has a new and very modern simulation centre with high-fidelity equipment.

The project partners tested the prototype of the NESTLED program in three testing sites: VIA University College, Metropolia University of Applied Sciences and Tallinn Health Care College. All these testing sites had simulation centres. The lack of skilled simulation-based learning facilitators to use the simulation centres was a common problem for all three sites. The aim of the testing was to detect difficulties, identify challenges associated with transfer and operationalization, and evaluate student satisfaction and learning outcomes. In all sites (Denmark, Finland, Estonia), at least two simulation facilitators were delivering the NESTLED program. Ethical principles were followed during the testing according to the relevant protocols of each university. The participants in the pilots received both oral and written information on the study before consenting to participate. Written consent was obtained from all participants (World Medical Association, 2013). All interviews were conducted in English. The data were anonymized and confidentiality was maintained.

\section{Phases 4 and 5}

The prototype was first tested at VIA University College in Denmark in August 2014 as a four-day training course. Eleven nurse educators participated and three members of the NESTLED project team facilitated the program with two technicians. Analysis revealed that four consecutive days in a row did not allow the participants enough time to reflect upon their learning. From the feedback, it was revealed that participants benefitted from the course and found it enjoyable. A number of the participants struggled with taking enough time away from their work responsibilities, and were consistently mindful of other role conflicts. Some of the participants voiced a desire to have more time to internalize the simulation pedagogy. Participants also felt that they would have benefitted from further information about learning theories than had been included in the prototype (Bøje et al., 2017). Based on these findings, changes were made to the timing of the NESTLED program's delivery at Metropolia University of Applied Sciences, Finland where the prototype was tested a second time. In addition, participants were given pre-reading material and individual assignments.

This second test of the prototype took place during the spring of 2015 . On this occasion, the course was held over five days that were spread over several weeks $(2+2+1$ days). Twelve nurse educators, two nurses and one emergency services manager participated. Three members of the NESTLED project team facilitated the program. In addition to completing the eight sessions (Table 1), the participants had two assignments to complete between the contact days. The first assignment was to plan, deliver and evaluate a simulation-based learning event, and the other assignment was to describe how to embed simulation-based learning into (the curriculum of) the participant's own organization. Analysis revealed that the Finnish participants had positive experiences of the theoretical sessions and that they enjoyed the practical sessions (Bøje et al., 2017). It was apparent that the participants felt it was really important that the education provided was grounded on a sound theoretical approach. Based on the results, it was also evident that the participants had a desire to improve their technical understanding of the equipment available or to be provided with technical support whilst delivering simulation sessions. It became apparent that a number of participants struggled to understand how the high-fidelity simulators operated. The majority of the participants felt that there could have been more 
simulation theory included. (Bøje et al., 2017). Based on this feedback, additional changes were made to the NESTLED program to place more of a focus on this area.

The prototype was tested for a third time at Tallinn College of Health, Estonia. Here the delivery of the program was spread over several weeks with a greater focus placed on simulation theory. During late spring and early autumn 2015, eight nurse educators participated in the program. Two members of the NETSLED project team facilitated the program. Analysis revealed that participants felt that the NESTLED program had opened their eyes to all the possibilities of the use and application of simulation pedagogy. Previously, the participants had used simulation pedagogy mainly for the evaluation of students' practical skills. The NESTLED program made them realize that simulation pedagogy can be used to teach theoretical subjects, interaction and interpersonal skills (Bøje et al., 2017).

The NESTLED model had now been piloted and tested and could be delivered as the NESTLED program to train educators to utilise SBL as a teaching and learning strategy. The NESTLED program is subject to ongoing evaluation and review by the NESTLED project team to ensure currency of content.

\section{Outcomes}

As an outcome of the development process, "the NESTLED model for educating simulation facilitators" (NESTLED model) was generated. The iterative cycles of testing and refining the model (i.e. the DBR approach) led to the development of the NESTLED model. In addition, the NESTLED model was operationalized into a deliverable NESTLED program. The NESTLED program consists of core elements that are considered compulsory in the delivery of the program. These core elements include facilitators' competencies and eight sessions. However, there are aspects of the program that require flexibility in terms of content and delivery. As an example of an adjustable element, the pedagogical solution can vary based on the background of the participating individuals. These core and adjustable elements are presented in Table 2.

\section{[INSERT TABLE 2 HERE]}

\section{Principles}

This design-based research process led to an improved understanding of how to educate simulation facilitators in the healthcare context, and the design principles were identified. This knowledge can be used in practice when designing and developing educational programs. The design principles for educating simulation facilitators are:

1. The competences of simulation facilitators embrace knowledge, behaviour and skills, and comportment in contrast to the more commonly used term 'attitudes.' It is clearly evident that effective simulation-based learning demands a multi-skilled educator. In addition, the effective educator demonstrates attributes labelled as 'comportment', which appears to be a multi-faceted concept as it aggregates a range of attributes, such as bringing theory to life, ability to maintain emotionally safe learning environments, acting as a professional role model, etc. (Topping et al., 2015).

2. Simulation facilitators fulfil their roles as coaches and experts instead of 'deliverers of knowledge' (Keskitalo, 2011; Keskitalo et al., 2011; Topping et al., 2015). 
3. Simulation facilitators need time to adjust to the new type of facilitator training that requires active involvement in learning processes. (Danish pilot in this project).

4. Simulation facilitators need to practise the new pedagogical method to be able to acquire the competencies required and to learn how to apply the method. (All pilots in this project).

5. Simulation facilitators need to understand the learning theories so that they can apply the methods of simulation pedagogy in different and new contexts. (All pilots in this project).

These five principles have been applied to the NESTLED model for educating simulation facilitators (NESTLED model), but could possibly be applied to the development of other pedagogical methods as well (see Wang \& Hannafin, 2005).

\section{Discussion}

The results of this DBR project facilitated the generation of "the NESTLED model for educating simulation facilitators" (NESTLED model) and further, it identified five design principles for educating simulation facilitators. With regard to the benefits, challenges and limitations of DBR (Wang \& Hannafin, 2005), this study was strengthened by basing the design of the NESTLED model on the systemized rapid review and synthesis (Topping et al., 2015) and refinement of the existing programs at the University of Huddersfield, Metropolia University of Applied Sciences and VIA University College. As discussed above, these heavily influenced the development of the prototype. The iterative cycles of testing and refining the model (see Barab \& Squire 2004; Wang \& Hannafin, 2005) produced new knowledge that was applied when defining the core and adjustable elements for the final NESTLED program. In addition, multiple data was collected, analysed, evaluated and reported. Nevertheless, the fact that the prototype was influenced by existing programs may be seen as a limitation due to the project team members' close relationship to, and ownership of, such programs. This may have had the effect of hindering their ability to 'look beyond' in order to become more deeply involved in creating new, and more innovative, evidence-based programs. Ethical principles were followed during all stages of data collection and analysis (World Medical Association, 2013). Ethical considerations were addressed by seeking the ethical approval of the institutional boards and giving the participants information letters describing the study and informed consent forms to sign.

The project was strengthened by the close collaboration of researchers and simulation educators/facilitators from three different countries. One of the biggest strengths of this study was the involvement of practitioners-simulation educators from three universities-who had real-life experience in facilitating simulation-based learning. They gave important insight into the development of the NESTLED model and the NESTLED program throughout the research process. Sanders (2002) has highlighted the importance of the participants' knowledge of the user, and translating that into design principles. In addition, the participants made an important contribution to further developing the model. Ensuring the long-term involvement of participants is one of the biggest challenges in design-based research (Leeman \& Wardekker, 2011). This experience was no different, and there were challenges in collaboration during the two-year project. During the project period, some of the initial project member workers moved abroad and left the project. Due to each university's policies, different people 
participated in the face-to-face meetings and some of the information might have disappeared during the information transfer and translation. The actual publication process was further impacted upon and complicated because of the turnover of personnel and competing demands to meet other deadlines.

Another challenge was the use of the English language, which might be one of the reasons that the dataset was small: 21 participants attended the focus group interviews and twelve participants completed both the pre- and postprogramme questionnaires (Bøje et al., 2017). Some of the participants refused to participate in the interviews because they were not confident in their ability to use English as the medium of communication. Furthermore, during the interview process, there were times at which participants were not confident in articulating their thoughts, finding the right words, and sometimes they could find no English equivalent when translating a word from their native language.

One of the issues that emerged from this DBR project is the ongoing international collaboration among universities that were involved in the project. Collaboration enables to test the NESTLED model in different international settings, redesign the design principles, and develop the model further (see Koivisto et al., 2018; Amiel \& Reeves, 2008).

\section{Conclusion}

The purpose of this article was to introduce the concept of design-based research, its appropriateness in creating education-based models, and to describe the process of developing such a model. The results of this study include generation of the NESTLED model and reusable design principles. The current data highlight the importance of the competences of simulation facilitators in order to fulfil educators' roles as coaches and experts instead of 'deliverers of knowledge'. These findings have significant implications for the understanding of how simulation facilitators need to practise the new pedagogical method to be able to apply the method successfully. The present study makes several noteworthy contributions to researcher and practitioners planning to utilise design-based research methodology in designing and developing new innovative learning environments and educational models in new international settings.

The NESTLED program is now being used to train nurse educators to become simulation facilitators in each of the project's participating countries. In addition, the tested model can be used for the quality assurance of the education and skills of the facilitators of simulation-based teaching, both nationally and internationally. In this respect, the model is working, but more research is needed in the future to further test the model and training, especially in the broader international context and across different disciplines and contexts. It has to be further considered that emerging technologies within simulation-based learning have an impact upon the technical knowledge required by the facilitators. This could potentially expand and add further perspectives to the NESTLED program and the research on simulation-based learning. 


\section{References}

Adamson, K. A. (2009). Integrating human patient simulation to nursing curriculum. Clinical Simulation in Nursing, 5, 129-155.

Amiel, T., \& Reeves, T. C. (2008). Design-based research and educational technology: Rethinking technology and the research agenda. Educational Technology \& Society, 11(4), 29-40.

Amin, H. J., Aziz, K., Halamek, L. P., \& Beran, T. N. (2013). Simulation-based learning combined with debriefing: trainers' satisfaction with a new approach to training the trainers to teach neonatal resuscitation. BMC Research Notes, 6, 251. doi:10.1186/1756-0500-6-251 
Anderson, M., Bond, M. L., Holmes, T. L., \& Cason, C. L. (2012). Acquisition of simulation skills: Survey of users. Clinical Simulation in Nursing, 2, 59-65. doi:10.1016/j.ecns.2010.07.002

Barab, S., \& Squire, K. (2004). Design-based research: Putting a stake in the ground. The Journal of the Learning Sciences, 13(1), 1-14. doi:10.1207/s15327809jls1301_1

Bentley, R., \& Seaback, C. (2011). A faculty development collaborative in interprofessional simulation. Journal of Professional Nursing, 27(6), e1-e7. doi:10.1016/j.profnurs.2011.08.009

Bland, A. J., Topping, A., \& Tobbell, J. (2014). Time to unravel the conceptual confusion of authenticity and fidelity and their contribution to learning within simulation-based education. Nurse Education Today, 34(7), 1112-8. doi.org/10.1016/j.nedt.2014.03.009

Bland, A. J., Topping, A., \& Wood, B. (2011). A concept analysis of simulation as a learning strategy in the education of undergraduate nursing students. Nurse Education Today, 31(7): 664-670. doi: 10.1016/j.nedt.2010.10.013

Boyatzis, R. (1982). The competent manager: A model for effective performance. New York: Wiley.

Bøje, R.B., Bland, A., Sutton, A., Hartvigsen, T., Hannula, L., Koivisto, J-M., RaussiLehto, E. \& Prescott, S. (2017). Developing and Testing transferability and feasibility of a Model for Educators Using Simulation-Based Learning - A European Collaboration, Nurse Education Today, 58, 53-58. doi: 10.1016/j.nedt.2017.08.005

Cant, R.P. \& Cooper, S.J. (2017). The value of simulation-based learning in prelicensure nurse education: A state-of-the-art review and meta-analysis. Nurse Education in Practice, 27, 45-62. doi:10.1016/j.nepr.2017.08.012

Cant, R. P., \& Cooper, S. J. (2009). Simulation-based learning in nurse education: Systematic review. Journal of Advanced Nursing, 66(1), 3-15. doi: 10.1111/j.1365-2648.2009.05240.x

Clapper, T. (2010). Beyond Knowles: What those conducting simulation need to know about adult learning theory. Clinical Simulation in Nursing, 6, e7-e14. doi:10.1016/j.ecns.2009.07.003 
Fisher, R. (2007). SimTeacher.com: An online simulation tool for teacher education. TechTrends, 51(1), 44-47.INACSL Standards Committee (2016).

INACSL standards of best practice: Simulation SM Simulation design. (2016) Clinical Simulation in Nursing,12(S), S5-S12. http://dx.doi.org/10.1016/j.ecns.2016.09.005.

Jeffries, P. (2008). Getting in S.T.E.P. with simulations: Simulations take educator preparation. Nursing Education Perspectives, 29(2), 70-73.

Kaakinen, J., \& Arwood, E. (2009). Systematic review of nursing simulation literature for use of learning theory. International Journal of Nursing Education Scholarship, 6(1), 1-20. doi:10.2202/1548-923X.1688

Keskitalo, T. (2011). Teachers' conceptions and their approaches to teaching in virtual reality and simulation-based learning environment. Teachers and Teaching: Theory and Practice, 17(1), 131-147.

Keskitalo, T., Pyykkö, E., \& Ruokamo, H. (2011). Exploring the meaningful learning of students in Second Life. Educational Technology and Society, 11(3), 16-26. Available at http://www.ifets.info/journals/14 1/3.pdf

Koivisto, J-M., Haavisto, E., Niemi, H., Haho, P., Nylund, S., \& Multisilta, J. (2018) Design principles for simulation games for learning clinical reasoning: A designbased research approach. Nurse Education Today, 60, 114-120. doi: 10.1016/j.nedt.2017.10.002.

LaFond, C., \& Van Hulle C. (2012). A critique of the National League for Nursing/Jeffries simulation framework. Journal of Advanced Nursing, 69(2), 465-480. doi: 10.1111/j.1365-2648.2012.06048.x

Lancaster, R. J. (2014). Serious game simulation as a teaching strategy in pharmacology. Clinical Simulation in Nursing, 10(3), e129-e137. doi:10.1016/j.ecns.2013.10.005

Leeman, Y. \& Wardekker, W. (2011). Redesigning vocational education: The possibilities of design-based research. Journal of Curriculum Studies, 43(3), 313-331. doi:10.1080/00220272.2011.557838

Liaw, S. Y., Zhou, W. T., Lau, T. C., Siau, C., \& Chan, S. W. (2014). An interprofessional communication training using simulation to enhance safe care for a deteriorating patient. Nurse Education Today, 34(2), 259-264. doi:10.1016/j.nedt.2013.02.019 
Mulder, M. (2014). Conceptions of professional competence. In S. Billett, C. Harteis, \& H. Gruber (Eds.), International handbook of research in professional and practice-based learning. (pp. 107-137) Springer International Handbooks of Education.

Mulder, M. (2012). Competence-based education and training. The Journal of Agricultural Education and Extension, 18(3), 305-314. doi:10.1080/1389224X.2012.670048

Mulder, M., Weigel, T., \& Collins, K. (2007). The concept of competence concept in the development of vocational education and training in selected EU member states. A critical analysis. Journal of Vocational Education and Training, 59(1), 65-85.

Muller, M., \& Gulikers, J. (2011). Workplace learning in East Africa. A case study. In M. L. Malloch, K. Cairns, K. Evans, \& B. O'Conner (Eds.), The SAGE handbook of workplace learning (pp. 307-318). London: SAGE.

Plomp, T. (2013). Educational design research: An introduction. In T. Plomp, \& N. Nieveen (Eds.), Educational design research part A. Netherlands Institute for Curriculum Development (SLO) (pp. 10-51). Enschede, the Netherlands. ISBN: 9789032923341

Reeves, T. (2006). Design research from a technology perspective. In J. van den Akker, K. Gravemeijer, S. McKenney, \& N. Nieveen (Eds.), Educational design research (pp. 52-66). London and New York: Routledge.

Roberts, D., \& Greene, L. (2011). The theatre of high-fidelity simulation education. Nurse Education Today, 31(7), 694-698. doi:10.1016/j.nedt.2010.06.003

Sandoval, W. A, \& Bell, P. (2004). Design-based research methods for studying learning in context: Introduction. Education Psychologist, 39(4), 199-201.

Spencer, L., \& Spencer, S. (1993). Competence at work: Models for superior performance. New York: John Wiley \& Sons.

Topping, A., Buus Larsen, R., Rekola, L., Hartvigsen, T., Prescott, S., Bland, A., Hope, A., Haho, P., \& Hannula, L. (2015). Towards identifying nurse educator competencies required for simulation based learning: A systemized rapid review and synthesis. Nurse Education Today, 35, 1108-1113. DOI: 10.1016/j.nedt.2015.06.003 
Walsh, M. (2011). Narrative pedagogy and simulation: Future directions for nursing education. Nurse Education in Practice, 11(3), 216-219. doi:10.1016/j.nepr.2010.10.006

Vathanophas, V., \& Thai-ngam, J. (2007). Competency requirements for effective job performance in the Thai public sector. Contemporary Management Research, 3(1), 45-70.

Wang, F., \& Hannafin, M. J. (2005). Design-based research and technology-enhanced learning environments. Educational Technology Research \& Development, 53(4), 5-23. ISSN 1042-1629

World Medical Association. WMA Declaration of Helsinki-ethical principles for medical research involving human subjects. (2013). http://www.wma.net/en/30publications/10policies/b3/ Accessed 10.05.16.

Zemke, R. (1982). Job competencies: Can they help you design better training? Training, 19(5), 28-31. 